\title{
Consequences of Zuspan Protocol Applications in Eclampsia Pregnant Women and Seizures
}

Bilge Aslan', Feray Aydın², Özlem Moraloğlu ${ }^{3}$

${ }^{1}$ Zekai Tahir Burak Training and Research Hospital, Department of Anesthesia, Ankara, Turkey.

${ }^{2}$ Zekai Tahir Burak Training and Research Hospital, Department of General Surgery, Ankara, Turkey

${ }^{3}$ Zekai Tahir Burak Training and Research Hospital, Department of Obstetrics, Ankara, Turkey

Corresponding Author: Bilge Aslan, Zekai Tahir Burak Training and Research Hospital, Department of Anesthesia, Ankara, Turkey.

Received date: May 07, 2021; Accepted date: August 14, 2021; Published date: September 252021

Citation: Aslan B., Aydın F., Moraloğlu O. (2021) High Complexity Fertilization in Cuba: Egg Donation. J Obstetrics Gynecology and Reproductive Sciences 5(8) DOI:10.31579/2578-8965/083

Copyright: (C) 2021, Bilge Aslan, This is an open access article distributed under the Creative Commons Attribution License, which permits unrestricted use, distribution, and reproduction in any medium, provided the original work is properly cited.

\begin{abstract}
Backgraund: Magnesium sulfate is the preferred anticonvulsant in the prevention and control of eclamptic convulsions. The Zuspan Regime is one of the most popular protocols used. However, due to toxicity concerns, several low-dose regimens have been implemented, given the low body mass index of Asian women. In our hospital, Zuspan Protocol is generally applied.

Objective: We aimed to compare the results, effectiveness and reliability of 6-hour and 12-hour intravenous (i.v) MgSO4 infusions in the Zuspan Protocol in our hospital.

Methods and Materials: A total of 700 cases of eclampsia were examined and these cases were treated with the Zuspan Protocol. The patients in the first group received 6 hours of treatment (n: 400), while the second group (n: 300) received the 12-hour treatment with magnesium sulfate. Recurrent convulsion rates, maternal and perinatal results of both regimens were evaluated and compared using unpaired t-test and chi-square test, respectively, for continuous and categorical variables.
\end{abstract}

Result: We detected 700 eclamptic cases among 50.620 births in our hospital during the 7-year working period and this rate was found as $80.5 \%$ of 700 women were in the 19-30 age group. Despite the fact that MgSO4 was infused in 700 eclamptic pregnant women, the rate of seizures was found to be total $3.57 \%$.

Conclusion: The 12-hour intravenous Zuspan Protocol was found to be more effective and more preventive and safer than the eclamptic seizure compared to the 6-hour Zuspan Protocol.

Keywords: eclampsia; pregnancy; eclampsi; magnesium sulfate; eclamptic seizures

\section{Introduction}

Preeclampsia and eclampsia incidence in preeclampsia-eclampsia syndrome (PES), maternal and perinatal morbidity and mortality and prenatal centers is $2.16 \%$ and $0.28 \%$ [1]. The suitable figures in India are $1.97 \%$ and $0.43 \%$ (1). Hypertension is present in the story of $14 \%$ of all maternal deaths, it is the second most common cause of maternal deaths worldwide [2]. There are four times and eight times more risks for preeclampsia and eclampsia. PES can be accompanied by various maternal complications such as Common Intravascular Coagulation (DIC), Kidney Failure, Hemolysis, High Liver Enzymes and Low Platelet (HELLP) syndrome, coma and pulmonary edema.

Pregnancy is a state of hypomagnesaemia. $\mathrm{Mg}^{+2}$ affects the contraction and the tone of the blood vessels, so Blood Pressure (BP) is regulated.
$\mathrm{Mg}^{+2}$ depletion has been shown to be the cause of one of the etiologies of PES $[1,4]$.

Background: Although the definitive treatment of pre-eclampsia and eclampsia is childbirth which the control of convulsions is the first and foremost principle of eclampsia management. Magnesium sulfate $\left(\mathrm{MgSO}_{4}\right)$ is the preferred anticonvulsant because it reduces the fetomaternal morbidity and mortality, as well as controlling and preventing eclamptic convulsions more effectively than diazepam and phenytoin [5,6]. Recommended therapeutic serum $\mathrm{Mg}^{+2}$ concentrations for effective control of eclamptic convulsions are 3.5-7 mEq / L (4.2-8.4 mg / dL) [7]. After convulsion; Due to developing apnea and aspiration, fetal distress may develop, but fetal distress disappears by controlling convulsion and applying supportive measures. Therefore, treatment of convulsion should be provided as the first measure. It should be known that the emergency caesarean which is applied immediately after the removal of the 
convulsion or because of the overlapping convulsion will not decrease the morbidity and mortality in the pregnant, but will increase it further. Anesthesia to be applied at this time will put the mother at maximum risk. Most importantly, the risk of cerebral bleeding and edema in these patients is significantly increased. For these reasons, delivery should be provided after the general condition of the pregnant has stabilized, that is, (4-6 hours on average) [19].

Injectable labetalol and / or oral nifedipine was administered at standard doses in a hypertensive crisis (HP: 160/110 mmHg). Antenatal corticosteroids were used for fetal lung maturity in expected preterm delivery cases. All patients were monitored hourly for Blood Pressure (BP), Respiratory Rate (RR), oxygen saturation, Deep Tendon Reflexes (DTR) and urine output.

\section{Material and Method:}

The working period was determined as pre-eclamptic and eclamptic pregnants who were followed up in Zekai Tahir Burak Training and Research Hospital between 2010-2017. The cases were screened retrospectively. Permission was obtained from the Regional Ethics Committee of Zekai Tahir Burak Training and Research Hospital before the study was conducted (Ethic No: 2018-12). The main purpose of this study is to investigate the results of 6-hour and 12-hour Zuspan regimen and intravenous (i.v) $\mathrm{MgSO}_{4}$ treatment and how it affects the rate of eclamptic seizures. A total of 700 cases of eclampsia were treated with the Zuspan Regimen. In Zuspan Regimen, 4 - 6 g intravenous loading dose is applied within 15 minutes, followed by $\mathrm{MgSO}_{4}$ perfusion to 1-2 $\mathrm{g} /$ hour. If convulsions are repeated in $10-15 \%$ of patients, the administration of $2 \mathrm{~g}$ of $\mathrm{MgSO}_{4}$ in the form of a bolus is mostly effective. In cases where convulsions continue despite these treatments, $10 \mathrm{mg}$ diazepam was given slowly intravenously (i.v). Women who had epilepsy and convulsions 5 days after the partum were excluded from the study. The maintenance dose is usually $2 \mathrm{~g} / \mathrm{hr}$, but the hourly infusion ranges from 0.5 to $3 \mathrm{~g}$. postpartum treatment time was generally 24 hours.

Protocol: After 10-15 minutes dilution in $50 \mathrm{cc} 5 \%$ Dextrose, intravenous $4 \mathrm{mg} \mathrm{50 \%} \mathrm{MgSO}_{4}$ loading dose was given. Following the loading dose, $\mathrm{MgSO}_{4}$ infusion was applied to 1-2 $\mathrm{g} / \mathrm{h}$. If convulsions occur again within 30 minutes of starting treatment, no additional $\mathrm{MgSO}_{4}$ is given. Convulsions are considered recurrence if not controlled even 30 minutes after a single dose of $\mathrm{MgSO}_{4}$ is given. Some patients switched to other regimens, such as Sardesai's low-dose $\mathrm{MgSO}_{4}$ regimen, i.e. $4 \mathrm{~g}$ $\mathrm{MgSO}_{4}$ was given as a loading dose and then $2 \mathrm{~g} \mathrm{MgSO}_{4}$ (diluted intramuscularly or intravenously) every 3 hours as a maintenance dose. Alternatively, the standard Pritchard Regimen (1,16-18), consisting of 5 $\mathrm{g} \mathrm{MgSO}_{4}$, was administered according to the eligibility criteria based on clinical evaluation of tendon reflexes, respiratory rate and urine every 4 hours or every hour. Since the loading dose of $\mathrm{MgSO}_{4}$ has already been given, only low dose $\mathrm{MgSO}_{4}$ [2] or Pritchard [1] maintenance dose has been used in relapse cases. Patients with regimen changes were excluded from the study.

Patients were monitored for magnesium toxicity and were prepared to treat any toxicity that may contain $10 \%$ calcium gluconate. Oral nifedepine was used as the anti-hypertensive agent. $8 \mathrm{mg} 10 \mathrm{mg}$ nifedepine was used per hour. If blood pressure $>160 / 110 \mathrm{~mm} \mathrm{Hg}$, an additional dose of $10 \mathrm{mg}$ was used every 30-45 minutes, up to a maximum dose of $80 \mathrm{mg} /$ day. The given fluid replacement therapy was Ringer's Lactate liquid or normal Saline. Underlying diseases / related complications were also recorded. An input-output monitoring was performed and termination of pregnancies was always planned. Liver function test, kidney function test, platelet count and other routine biochemical examinations were also performed in these women.

\section{Results:}

We detected 700 eclamptic cases among 50.620 births in our hospital during the 7-year working period $(2010-2017)$ and this rate was found as $80.5 \%$ of 700 women were in the $19-30$ age group. Only $3 \%$ of women were over 30 years old. $80 \%$ of women were primigravid. The mean age was 23.5 , with a standard deviation of 3.5 . The mean gestational age was 33.4 weeks with 1.34 standard deviations. In $60 \%$ of cases, the gestational age was under 34 weeks. The 12-hour prophylactic i.v administered Zuspan Regimen significantly reduced seizure rate compared to the 6hour Zuspan Regimen [Table-1].

\begin{tabular}{|c|c|c|c|}
\hline & $\begin{array}{l}12 \text { hours Magnesium Sul } \\
\text { infusion, } \mathrm{N}=400\end{array}$ & $\begin{array}{l}6 \text { hours Magnesium Sul } \\
\text { infusion, } N=300\end{array}$ & $\mathrm{P}$ values \\
\hline Hypertensive disorder, N (\%) & $360(90)$ & $270(90)$ & 0.65 \\
\hline Severe eclampsia & $320(80)$ & $243(81)$ & 0.68 \\
\hline Recurrent eclampsia $^{a}$ & $80(20)$ & $57(19)$ & 0.01 \\
\hline Age - SD (year) & $25.1 \pm 7.5$ & $26.4 \pm 5.4$ & 0.65 \\
\hline Number of pregnancy & $2.4(1.6)$ & $2.1(1.7)$ & 0.23 \\
\hline Average gestational age (weel & $34.4(2.6)$ & $35.1(3.1)$ & 0.23 \\
\hline Symptom $^{\mathrm{b}}(\%)$ & $248(62)$ & $180(60)$ & 0.73 \\
\hline $\begin{array}{l}\text { Systolic Pressure } \mathrm{mmHg}, \mathrm{I} \\
\text { (SD) }\end{array}$ & $160 \pm 13.2$ & $154 \pm 17.1$ & 0.02 \\
\hline $\begin{array}{l}\text { Diastolic Pressure } \mathrm{mmHg}, \mathrm{Me} \\
\text { (SD) }\end{array}$ & $100 \pm 9.9$ & $105.3 \pm 10.8$ & 0.24 \\
\hline Labetolol (mg, i.v) & $100(25 \%)$ & $90(30 \%)$ & 0.32 \\
\hline Nifedipine (mg) & $300(75 \%)$ & $200(66.6 \%)$ & 0.36 \\
\hline Hidrazalin $(10 \mathrm{mg}, \text { i.v })^{\mathrm{c}}$ & $50(12.5 \%)$ & $100(33.36 \%)$ & 0.023 \\
\hline $\mathrm{Mg}^{2+}(4.2-8.4 \mathrm{mg} / \mathrm{dL})$ & $4.7 \pm 1.4$ & $4.5 \pm 1.5$ & 0.14 \\
\hline $\begin{array}{l}\text { How many hours after thelo } \\
\text { dose occurred (SD) }\end{array}$ & $5.6(2.3)$ & $4.5(3.8)$ & 0.82 \\
\hline Cesarean Section ratio, N (\%) & $280(70)$ & $240(80)$ & 0.50 \\
\hline Seizure rate, $\mathrm{N}(\%)^{\mathrm{d}}$ & $10(2.5)$ & $15(3.75)$ & 0.021 \\
\hline $\begin{array}{l}\text { Diazepam (10mg, i.v) given, } \\
(\%)^{\mathrm{e}}\end{array}$ & $8(2)$ & $10(3.3)$ & 0.03 \\
\hline
\end{tabular}


${ }^{a}$ Chronic blood pressure with severe features of overlapping preeclampsia.

bOne or more symptoms: Severe headache, visual disturbances, epigastric pain.

${ }^{\mathrm{c}}$ Hidrazalin iv administration dose was higher in the 12-hours Mg infusion than in the 6-hours Mg infusion.

${ }^{\mathrm{d}}$ The rate of seizures was higher in the 12-hours Mg infusion than in the 6-hours Mg infusion.

eDiazepam iv administration dose was higher in the 12-hours Mg infusion than in the 6-hours Mg infusion.

Table1: Results of the Zuspan Protocols applied for $6 \mathrm{~h}$ i.v infusion or $12 \mathrm{~h}$ i.v infusion hours.

\section{Discussion:}

Magnesium sulfate $\left(\mathrm{MgSO}_{4}\right)$ is one of the critical interventions needed to reduce serious negative consequences from preeclampsia / eclampsia. It is the drug of choice for both prevention and treatment of eclampsia; in women with preeclampsia, it is important that the risk of eclampsia is halved and superior to diazepam or phenytoin treatment [6, 7.15]. Currently, the World Health Organization (WHO) and other international organizations are recommending two $\mathrm{MgSO}_{4}$ regimens for eclampsia prophylaxis, the Pritchard Regimen: i.e. predominantly administered intramuscularly, and the intravenously administered Zuspan regimen is widely used [6, 8-10, 19]. Despite global efforts, translating this information into clinical practice has been challenging in many countries. Considering the barriers to access and use of the currently proposed $\mathrm{MgSO}_{4}$ regimens, a simplified regime needs to be further investigated with a low-quality multi-country trial at all levels of health system and to derive a broadly applicable viable clinically effective regimen [11-14]. Socioeconomic environments can potentially minimize material and skilled staff shortage challenges that prevent wider implementation of the currently proposed clinical practice with such a simplified regime.

Consequence: The 12-hour Zuspan Protocol was statistically more effective and safer than the 6-hour Zuspan regime. The Zuspan Protocol is a simple and painless intravenous administration. The 12-hour prophylactic i.v administered Zuspan Regimen significantly reduced seizure rate compared to the 6-hour Zuspan Regimen (\%2.5 versus \% $3.75)$.

\section{References:}

1. Abalos E, Cuesta C, Grosso AL, Chou D, Say L. (2013)Global and regional estimates of preeclampsia and eclampsia: a systematic review. Eur J Obstet Gynecol Reprod Biol x;170:1-7.

2. Duley L. (2009) The global impact of pre-eclampsia and eclampsia. Semin Perinatol ;33:130-7.

3. Vigil-De Gracia P. (2009) Maternal deaths due to eclampsia and HELLP syndrome. Int J Gynaecol Obstet ;104:90-4.

4. Say L, Chou D, Gemmill A, Tunçalp Ö, Moller AB, Daniels J, et al. (2014)Global causes of maternal death: a WHO systematic analysis. Lancet Glob Health ;2:e323-33.

5. World Health Organization . (2011)WHO Recommendations for Prevention and Treatment of Pre-eclampsia and Eclampsia. Geneva: World Health Organization;

6. Duley L Gülmezoglu AM, Henderson-Smart DJ, Chou D. (2010) Magnesium sulphate and other anticonvulsants for women with pre-eclampsia. Cochrane Database Syst Rev ;11:CD000025
7. National Institute for Health and Care Excellence (NICE) . (2010) Hypertension in Pregnancy. Clinical guideline [CG107]. London: NICE

8. Magee LA, Pels A, Helewa M, Rey E, von Dadelszen P, SOGC Hypertension Guideline Committee. Diagnosis, evaluation, and management of the hypertensive disorders of pregnancy: executive summary. J Obstet Gynaecol Can 2014;36:575-6.

9. Smith JM, Currie S, Cannon T, Armbruster D, Perri J. Are national policies and programs for prevention and management of postpartum haemorrhage and preeclampsia adequate? A key informant survey in 37 countries. Glob Health Sci Pract 2014;2:275-84

10. 8 Bigdeli M, Zafar S, Assad H, Ghaffar A. Health system barriers to access and use of magnesium sulfate for women with severe pre-eclampsia and eclampsia in Pakistan: evidence for policy and practice. PLoS One 2013;8:e5915.

11. Oguntunde O, Charyeva Z, Cannon M, Sambisa W, Orobaton N, Kabo IA, et al. (2015) Factors influencing the use of magnesium sulphate in pre-eclampsia/eclampsia management in health facilities in North Nigeria: a mixed methods study. BMC Pregnancy Childbirth ; 15:130.

12. Tran DN, Bero LA. Barriers and facilitators to the quality use of essential medicines for maternal health in low-resource countries: an Ishikawa framework. J Global Health ;5:010406.

13. Barua A, Mundle S, Bracken H, (2011)Easterline T, Winikoff $B$. Facility and personnel factors influencing magnesium sulfate use for eclampsia and pre-eclampsia in 3 Indian hospitals. Int $J$ Gynecol Obstet ;115:231-4.

14. Mol BW, Roberts CT, (2016)Thangaratinam S, Magee LA, de Groot CJ, Hofmeyr GJ. Pre-eclampsia. Lancet ;387:999-1011.

15. Salinger DH, Mundle S, Regi A, Bracken H, Winikoff B, Vicini $\mathrm{P}$, et al. Magnesium sulphate for prevention of eclampsia: are intramuscular and intravenous regimens equivalent? A population pharmacokinetic study BJOG 2013;120:894-900.

16. Pratt JJ, Niedle PS, Vogel JP, 2016 Oladapo OT, Bohren M, Tuncalp Ö, et al. Alternative regimens of magnesium sulfate for treatment of preeclampsia and eclampsia: a systematic review of non-randomized( studies. Acta Obstet Gynecol Scand 2016;95:144-56.

17. Zuspan FP, Zuspan KJ: Antihypertensive therapy during pregnancy. In Raybum WF, Zuspan FP (eds) Drug therapy in Obstetrics and Gynecology. St Louis, Mosby Year Book. 105126, 1992. 